\title{
Successful Management of Intentional Amlodipine Poisoning: A Survival Experience of Health Care Worker
}

\author{
Chaitanya Gupta $^{1}$, Amitabh Satsangi ${ }^{2 *}$ and Prashant Nath Gupta ${ }^{3}$ \\ ${ }^{l}$ Department of Medicine, Ramakrishnan Mission Sevashram Hospital, Vrindavan, India \\ ${ }^{2}$ Department of Cardiothoracic and Vascular Surgery, All India Institute of Medical Sciences, New Delhi, India \\ ${ }^{3}$ Department of Radiodiagnosis, Ramakrishnan Mission Sevashram Hospital, Vrindavan, India
}

Correspondence should be addressed to Amitabh Satsangi, amoeba418@gmail.com

Received Date: May 07, 2020; Accepted Date: May 20, 2020; Published Date: May 28, 2020

\begin{abstract}
Amlodipine is a calcium channel blockers and belongs to class Dihydropyridines and used to reduce systemic vascular resistance and arterial pressure. Nevertheless, they remain the major case of cardiovascular drug overdose that often leads to lethal outcome. We report the case of intoxication with Amlodipine. This caused severe hypotension, in young health care worker. Patient was initially treated in our ICU with leg and elevation, fluids, calcium gluconate, noradrenaline, glucagon.
\end{abstract}

\section{KEYWORDS}

Amlodipine; Cardiovascular drug; Arterial pressure

\section{INTRODUCTION}

Amlodipine is a commonly prescribed, easily available dihydropyridine calcium channel blocker which is widely used as an antihypertensive, antianginal agent in our country. According to American Association of poison centers calcium channel blockers accounts for approximately $40 \%$ of cardiovascular drug exposure [1].

Management of amlodipine intoxication is quite peculiar, and demands a thorough understanding of the underlying pathophysiology of the condition. Patients generally have profound refractory hypotension, hypotension and in extreme conditions cardiogenic shock and pulmonary edema which requires meticulous management [2]. Medical literature is flooded with fatal cases of amlodipine poisoning but there is a scarcity in Indian literature [3].

We report a survival case of an intentional amlodipine intoxication of a healthcare worker with no other concomitant substance ingestion who is managed conservatively without using hyperinsulinemia euglycemic therapy.

\section{CASE REPORT}

A 21-year-old female health worker with no comorbidities or any history of regular medication intake, presented with giddiness, stiffness all over body with frothing from mouth after consuming 25 tablets of Amlodipine (10 mg/tablet) with suicidal intentions and presented to emergency department approximately 4 hours after ingestions. Patient had clouded consciousness

Citation: Amitabh Satsangi, Successful Management of Intentional Amlodipine Poisoning: A Survival Experience of Health Care Worker. J Heart 1(1): 1-3. 
but anxious, afebrile, bradypnea, vitally patient's heart rate was 50 beats/min, blood pressure was $80 / 50 \mathrm{~mm} / \mathrm{hg}$ Spo2 - 88\%, GCS of the patient was 12, bilateral basal crepitus. Pupils were equally reactive, and she had oliguria, followed by rigidity of limbs and a possible seizure.

Intravenous access was established, nasogastric tube was inserted and a gastric lavage was performed and patient was resuscitated with IV fluids $(30 \mathrm{ml} / \mathrm{kg})$. Patient's blood sugar was $70 \mathrm{mg} / \mathrm{dl}$, patient was instantaneously shifted to intensive care unit; patient was still drowsy, heart rate dipped to $45 /$ minutes, blood pressure was unresponsive to fluid resuscitation, inotrope noradrenaline was started to support the blood pressure.

Initial hemogram, liver and renal function tests. There is no abnormality on CXR and electrocardiogram. Echocardiography revealed normal chamber size with normal LV systolic and diastolic function. ABG shows low ionic calcium $(1.19 \mathrm{mmol} / \mathrm{L})$ and serum calcium level was $7.9 \mathrm{mg} / \mathrm{dl}$.

$30 \mathrm{ml}$ of $10 \%$ calcium gluconate over 5 minutes followed by infusion of $10 \mathrm{ml} / \mathrm{hr}$ of calcium gluconate and was stopped after $3 \mathrm{hrs}$ when serum calcium level reached to $13.9 \mathrm{mg} / \mathrm{dl} .10 \mathrm{mg}$ of glucagon was administered intravenously as a stat dose $\&$ an infusion of glucagon at $3 \mathrm{mg} / \mathrm{hr}$ was continued for 3 hours and stopped after serum calcium level reached to $13.9 \mathrm{mg} / \mathrm{dl}$. Decision was taken to avoid hyperinsulinemic euglycemic protocol in view of blood sugars on the lower side.

With these measures, the patient started showing improvement in her hemodynamics, heart rate picked up to $100 / \mathrm{min}$, with blood pressure of $130 / 60 \mathrm{mmhg}$ and urine output improved to $1.5 \mathrm{ml} / \mathrm{kg} /$ hour. Patient deteriorate after 24 hours with dyspnea and clinical/radiological features suggestive of pleural effusion.
Pleural fluid aspiration was done and $1500 \mathrm{ml}$ clear fluid was withdrawn which relieve her symptom and sample send for testing which shows transudative fluid. Repeated echocardiogram revealed mild pericardial effusion. The patient was treated with diuretics and oxygen. Over the next 48 hours she showed gradual improvement in her clinical condition. Inotropes infusion were tapered and withdrawn after 72 hours of admission. On day $6^{\text {th }}$ she was discharged in good health after psychiatry consultation.

\section{DISCUSSION}

Calcium channel blockers (CCBs) have been increasingly used for a variety of cardiovascular conditions, such as hypertension, angina and supraventricular tachyarrhythmias.

Dihydropyridine CCBs have a predominant effect on vascular smooth muscle cells and little effect on cardiac pacemaker's cells or contractility when used in therapeutic doses [4].

In the condition of amlodipine poisoning the pharmacodynamics are aggravated leading to refractory hypotension and bradycardia.

The pathophysiology of the condition revolves around the inhibition of L-type calcium channels, which are found in pancreatic $\beta$-cells, as well as in the myocardium and in vascular smooth-muscle cells.

This results in insulin resistance induced decreased cardiac inotropism and peripheral vascular dilatation [5].

Calcium improves hypotension, conduction and contractility of heart. Kenny et al. has suggested $10 \mathrm{ml}$ of $10 \%$ calcium chloride or $20 \mathrm{ml}-30 \mathrm{ml}$ of calcium gluconate IV and depending on clinical response to be repeated 15 minutes - 20 minutes up to four doses with monitoring of serum calcium [6]. 
Glucagon $5 \mathrm{mg}-10 \mathrm{mg}$ iv dose is also used for management. Glucagon promotes calcium entry into cells via stimulation of a receptor that is considered to be separate from adrenergic receptors [7]. Hyperinsulinemia euglycemia technique has been used with remarkable success recently $[8,9]$.

Many other treatment modalities have been described in the literature. Transvenous pacing may be required in patients with severe symptomatic bradycardia not responding to atropine or isoprenaline infusion [6].

Standard cardiopulmonary bypass has been used in some cases to allow sufficient time for liver detoxification [10].
Extracorporeal membrane oxygenation was described in massive diltiazem overdose for temporary hemodynamic support [11].

Therapeutic plasma exchange was also utilized in the management of certain cases of Amlodipine overdose. Amlodipine overdose can be potentially fatal owing to non - cardiogenic pulmonary edema, refractory shock, and its management can be challenging. Outcome can be improved by early and aggressive intensive care, inotropic support, calcium infusion and other supportive measures [12].

\section{REFERENCES}

1. Bronstein AC, Spyker DA, Cantilena LR, et al. (2011) 2010 Annual report of the American association of poison control centers' national poison data system (NPDS): $28^{\text {th }}$ annual report. Clinical Toxicology 49(10): 910-941.

2. Agarwal A, Siegfried WY, Rehman A, et al. (2012) Hyperinsulinemia euglycemia therapy for calcium channel blocker overdose: A case report. Texas Heart Institute Journal 39(4): 575-578.

3. Rathore A, Ranjan NK, Sadananda KS (2017) A survival case of amlodipine poisoning. Indian Journal of Case Reports 3(4): 242-243.

4. Russell RP (1988) Side effects of calcium channel blockers. Hypertension 11(3_pt_2): II42.

5. Lheureux PE, Zahir S, Gris M, et al. (2006) Bench-to-bedside review: Hyperinsulinaemia/euglycaemia therapy in the management of overdose of calcium-channel blockers. Critical Care 10(3): 212.

6. Kenny J (1994) Treating overdose with calcium channel blockers.

7. Walter FG, Frye G, Mullen JT, et al. (1993) Amelioration of nifedipine poisoning associated with glucagon therapy. Annals of Emergency Medicine 22(7): 1234-1237.

8. Boyer EW, Shannon M (2001) Treatment of calcium-channel-blocker intoxication with insulin infusion. New England Journal of Medicine 344(22): 1721-1722.

9. Patel NP, Pugh ME, Goldberg S, et al. (2007) Hyperinsulinemic euglycemia therapy for verapamil poisoning: A review. American Journal of Critical Care 16(5): 498-503.

10. Hendren WG, Schieber RS, Garrettson LK (1989) Extracorporeal bypass for the treatment of verapamil poisoning. Annals of Emergency Medicine 18(9): 984-987.

11. Durward A, Guerguerian AM, Lefebvre M, et al. (2003) Massive diltiazem overdose treated with extracorporeal membrane oxygenation. Pediatric Critical Care Medicine 4(3): 372-376.

12. Ezidiegwu C, Spektor Z, Nasr MR, et al. (2008) A case report on the role of plasma exchange in the management of a massive amlodipine besylate intoxication. Therapeutic Apheresis and Dialysis 12(2): 180-184. 